\title{
Surgical and Audiologic Comparison Between Sophono and Bone-Anchored Hearing Aids Implantation
}

\author{
Joong-Wook Shin ${ }^{1} \cdot$ Sung Huhn Kim² $\cdot$ Jae Young Choi $^{2} \cdot$ Hong-Joon Park $^{1} \cdot$ Seung-Chul Lee ${ }^{1} \cdot$ Jee-Sun Choi ${ }^{1}$ \\ Han Q Park' ${ }^{1}$ Ho-Ki Lee ${ }^{1}$
}

${ }^{1}$ Soree Ear Clinic, Seoul; ${ }^{2}$ Department of Otorhinolaryngology, Yonsei University College of Medicine, Seoul, Korea

Objectives. Bone-anchored hearing aids (BAHA) occasionally cause soft tissue problems due to abutment. Because Sophono does not have abutment penetrating skin, it is thought that Sophono has no soft tissue problem relating to abutment. On the other hand, transcutaneous device's output is reported to be 10 to $15 \mathrm{~dB}$ lower than percutaneous device. Therefore, in this study, Sophono and BAHA were compared to each other from surgical and audiological points of view.

Methods. We retrospectively reviewed the medical records of 9 Sophono patients and 10 BAHA patients. In BAHA cases, single vertical incision without skin thinning technique was done. We compared Sophono to BAHA by operation time, wound healing time, postoperative complications, postoperative hearing gain after switch on, and postoperative air-bone gap.

Results. The mean operation time was 60 minutes for Sophono and 25 minutes for BAHA. The wound healing time was 14 days for Sophono and 28 days for BAHA. No major intraoperative complication was observed. Skin problem was not observed in the 2 devices for the follow-up period. Postoperative hearing gain of bilateral aural atresia patients was $39.4 \mathrm{~dB}$ for BAHA $(n=4)$ and $25.5 \mathrm{~dB}$ for Sophono $(n=5)$. However, the difference was not statistically significant. In all patients included in this study, the difference of air-bone gap between two groups was $16.6 \mathrm{~dB}$ at $0.5 \mathrm{kHz}$ and $18.2 \mathrm{~dB}$ at $4 \mathrm{kHz}$. BAHA was statistically significantly better than Sophono.

Conclusion. Considering the audiologic outcome, BAHA users were thought to have more audiologic benefit than Sophono users. However, Sophono had advantages over BAHA with abutment in cosmetic outcome. Sophono needed no daily skin maintenance and soft tissue complication due to abutment would not happen in Sophono. Therefore, a full explanation about each device is necessary before deciding implantation.

Keywords. Hearing Aids; Hearing Loss; Hearing Loss, Conductive; Aural Atresia, Congenital; Bone Conduction

\section{INTRODUCTION}

Bone-anchored hearing devices of percutaneous type have been successfully used to treat conductive hearing loss (HL) patients that cannot be corrected by surgery and single side deaf patients. Bone-anchored hearing aids (BAHA) are the most widely

\footnotetext{
- Received December 31, 2014

Revised June 15, 2015

Accepted June 19, 2015

- Corresponding author: Ho-Ki Lee

Soree Ear Clinic, 435, Hakdong-ro, Gangnam-gu, Seoul 06068, Korea

Tel: +82-2-542-5222, Fax: +82-2-542-5207

E-mail: earclinic@hanmail.net
}

used percutaneous type device. But skin penetrating abutment of BAHA occasionally develops soft tissue problems [1,2] and has poor aesthetic outcome. In addition, skin penetrating abutment demands daily cleaning around abutment during the lifetime. If the cleansing is insufficient, soft tissue infection, skin overgrowth around abutment, and osseointegration failure could occur more frequently.

Since 2013, a new bone-anchored hearing device of transcutaneous type, Sophono Alpha 2 system (Sophono Inc., Boulder, CO, USA) has been commercially available in Korea. Because Sophono does not have skin penetrating abutment, Sophono is thought to have no soft tissue problem relating to abutment and to have better aesthetic outcome. On the other hand, transcuta-

Copyright @ 2016 by Korean Society of Otorhinolaryngology-Head and Neck Surgery.

This is an open-access article distributed under the terms of the Creative Commons Attribution Non-Commercial License (http://creativecommons.org/licenses/by-nc/4.0)

which permits unrestricted non-commercial use, distribution, and reproduction in any medium, provided the original work is properly cited. 
neous device's output is reported to be 10 to $15 \mathrm{~dB}$ lower than percutaneous device $[3,4]$.

However, few reports have compared transcutaneous device with percutaneous device. Therefore, we conducted a retrospective study on nine Sophono patients in 2 hospitals who had implantation with Sophono with Alpha 2 processor and ten BAHA patients who had implantation with single vertical incision without skin thinning technique. Sophono and BAHA were compared to each other from surgical and audiological points of view.

\section{MATERIALS AND METHODS}

We performed BAHA surgery using single vertical incision without skin thinning technique since December 2009. There were ten BAHA patients. Sophono surgery was performed since December 2013. There were nine Sophono patients. We retrospectively review their medical records.
The 10 BAHA patients had an average age of 39.9 years (range, 12 to 62 years), including six men and four women. Their mean follow-up period was 25.3 months (range, 20 to 35 months). The causes of BAHA surgery included bilateral congenital aural atresia $(n=4)$, chronic ear infections $(n=3)$, and unilateral HL $(n=3)$. Two bilateral aural atresia patients previously underwent bilateral otoplasty. Another one underwent bilateral meatoplasty. Every BAHA patient except two bilateral aural atresia patients used Baha BP100 (Cochlear, Sydney, Australia). Two bilateral aural atresia patients used Baha BP110 (Cochlear).

Sophono patients had an average age of 28.1 years (range, 5 to 71 years), including 4 men and 5 women. Their mean followup period was 8.4 months (range, 4 to 12 months). The causes of Sophono surgery included bilateral congenital aural atresia $(n=5)$, unilateral congenital aural atresia $(n=1)$, chronic ear infections $(n=1)$, and unilateral HL $(n=2)$. Two bilateral aural atresia patients previously underwent bilateral meatoplasty and bilateral otoplasty. And another one bilateral aural atresia patient
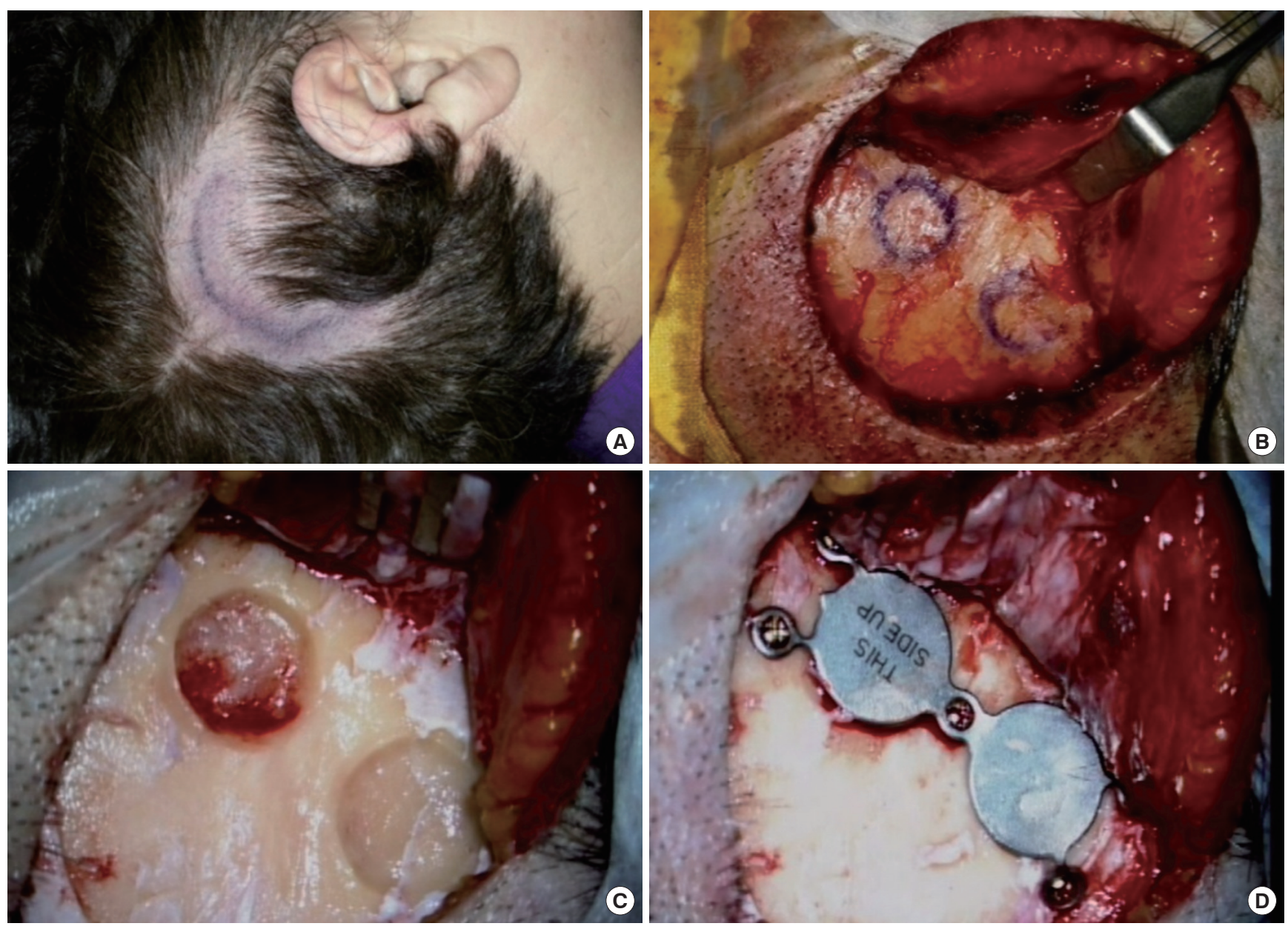

Fig. 1. Operative procedure of Sophono. (A) The curved skin incision is marked using the template. Seven to $8 \mathrm{~cm}$-sized curved incision was made along the template at the postauricular area. (B) The pericranium was dissected and elevated anteriorly enough to drill and insert the implantable component. (C) Well for implantable component was drilled. The recommended size of the well was $2.5 \mathrm{~mm}$ in depth and $10 \mathrm{~mm}$ in diameter. It could be gazed by the template. (D) Another drillings for five screws were done. After then, the implant was fixed by five titanium screws. 
was BAHA user who was included in this study. At first, he underwent bilateral meatoplasty to restore his hearing, but the hearing was unsatisfactory. After that, BAHA was performed with satisfactory result. However, he wanted to have binaural hearing. After we explained Sophono, he chose Sophono due to its better aesthetic outcome.

Single vertical incision without skin thinning technique was used for BAHA implantation as described previously [5]. Operative procedure of Sophono is presented in Fig. 1.

\section{Comparison parameters in this study}

We compared Sophono with BAHA by the operation time, wound healing time, postoperative complications, postoperative hearing gain after switch on, and postoperative air-bone (AB) gap. The operation time was calculated using operation record. The wound healing time was defined as the period from operation day to the day that regular outpatient visit for the wound care was no longer needed. Postoperative wound infection, skin overgrowth, reoperation, and other postoperative complications were investigated using medical record.

Postoperative hearing gain, postoperative $\mathrm{AB}$ gap: Mean airconduction $(\mathrm{AC})$, and bone-conduction $(\mathrm{BC})$ hearing were averaged at 4 audiometric frequencies (500, 1,000, 2,000, and 4,000 $\mathrm{Hz}$ ). Postoperative hearing gain was measured as unaided mean $\mathrm{AC}$ hearing minus aided mean free-field AC hearing. Postoperative $\mathrm{AB}$ gap was measured as aided mean free-field $\mathrm{AC}$ hearing minus mean $\mathrm{BC}$ hearing of better bone conduction ear. We regularly followed up the patients every three months. The latest free-field audiometry was used.

We used Mann-Whitney $U$-test for statistical analysis. A $P$-value $<0.05$ was considered statistically significant.

\section{RESULTS}

\section{Operation time and healing time}

The mean time required for surgery was 60 minutes (range, 40 to 105 minutes) for Sophono and 25 minutes (range, 20 to 30 minutes) for BAHA. The wound healing time was 14 days for Sophono and 28 days for BAHA. But, actual switch on of Sophono was started from 4 weeks after surgery.

\section{Postoperative complications}

In BAHA cases, there were 2 patients with abutment loosening. These cases were simply fixed at outpatient clinic. Skin infection, skin growth over the abutment, and fixture extrusion were not observed in any of these cases during follow-up period.

In Sophono cases, 2 patients complained about pain around the external base plate after processor switch-on. Pain disappeared after magnet strength change from strength 4 to strength 2. Other complications were not observed.

\section{Hearing improvement after switch on}

Tables 1 and 2 are the demographic data and individual audiologic data of study population. At first, we compared the hearing improvement after switch on in bilateral aural atresia cases. There were four bilateral aural atresia cases in BAHA and five bilateral aural atresia cases in Sophono. Unaided mean AC hearing of BAHA was $62.5 \mathrm{~dB}$ (standard deviation [SD], 1.8). Aided mean free-field AC hearing of BAHA was $23.1 \mathrm{~dB}(\mathrm{SD}, 8.9)$. Postoperative hearing gain was $39.4 \mathrm{~dB}(\mathrm{SD}, 8.6)$. Unaided mean $\mathrm{AC}$ hearing of Sophono was $54.5 \mathrm{~dB}$ (SD, 9.5). Aided mean free-field AC hearing of Sophono was $29 \mathrm{~dB}$ (SD, 10.8). Postoperative hearing gain was $25.5 \mathrm{~dB}$ (SD, 11.7). BAHA was better than Sophono in postoperative hearing gain. However, the difference was not statistically significant ( $P=0.063$ ) (Fig. 2).

Postoperative $\mathrm{AB}$ gaps of BAHA were $12.5 \mathrm{~dB}$ at $0.5 \mathrm{kHz}, 6.2$ $\mathrm{dB}$ at $1 \mathrm{kHz},-2.5 \mathrm{~dB}$ at $2 \mathrm{kHz}$, and $7.5 \mathrm{~dB}$ at $4 \mathrm{kHz}$. Postoperative $\mathrm{AB}$ gaps of Sophono were $21 \mathrm{~dB}$ at $0.5 \mathrm{kHz}, 10 \mathrm{~dB}$ at $1 \mathrm{kHz}$, $2 \mathrm{~dB}$ at $2 \mathrm{kHz}$, and $23 \mathrm{~dB}$ at $4 \mathrm{kHz}$. The difference of $\mathrm{AB}$ gap between 2 groups was $8.5 \mathrm{~dB}$ at $0.5 \mathrm{kHz}$ and $15.5 \mathrm{~dB}$ at $4 \mathrm{kHz}$. BAHA was better than Sophono in the AB gap. However, the difference was not statistically significant $(0.5 \mathrm{kHz}, P=0.17 ; 4$ $\mathrm{kHz}, P=0.16)$.

We compare the $\mathrm{AB}$ gap between the two groups, including the unilateral $\mathrm{HL}$ patients and other patients for measuring the

Table 1. Demographic data and individual audiologic data of Sophono

\begin{tabular}{|c|c|c|c|c|c|c|}
\hline No. & Sex/age (yr) & Etiology & Previous operative history & $\begin{array}{c}\text { Preop AC } \\
(0.5 / 1 / 2 / 4 \mathrm{kHz})\end{array}$ & $\begin{array}{c}\text { Aided AC } \\
(0.5 / 1 / 2 / 4 \mathrm{kHz})\end{array}$ & $\begin{array}{c}\text { Preop BC } \\
(0.5 / 1 / 2 / 4 \mathrm{kHz})\end{array}$ \\
\hline 1 & $F / 24$ & $\mathrm{BA}$ & Meatoplasty (B), Otoplasty (B) & $40 / 40 / 45 / 35$ & $25 / 15 / 15 / 30$ & $10 / 5 / 20 / 15$ \\
\hline 2 & $\mathrm{M} / 12$ & $\mathrm{BA}$ & Meatoplasty (B), Otoplasty (B) & $60 / 55 / 45 / 45$ & $35 / 15 / 20 / 35$ & $15 / 20 / 15 / 20$ \\
\hline 3 & $\mathrm{M} / 33$ & $\mathrm{BA}$ & & $65 / 55 / 55 / 60$ & $20 / 15 / 10 / 40$ & $10 / 15 / 20 / 15$ \\
\hline 4 & $\mathrm{~F} / 5$ & $\mathrm{BA}$ & & $70 / 70 / 60 / 60$ & $30 / 30 / 20 / 35$ & 0/10/20/10 \\
\hline 5 & $\mathrm{M} / 23$ & $\mathrm{BA}$ & Meatoplasty (B) & $45 / 45 / 50 / 90$ & $45 / 25 / 40 / 80$ & $15 / 0 / 20 / 40$ \\
\hline 6 & $\mathrm{~F} / 23$ & UA & & 65/60/55/65 & $55 / 45 / 30 / 60$ & 0/0/10/10 \\
\hline 7 & $\mathrm{~F} / 71$ & $\mathrm{COM}$ & Adhesive drums & 55/50/45/55 & $40 / 30 / 20 / 30$ & 15/15/20/25 \\
\hline 8 & $F / 9$ & UHL & Idiopathic & 65/90/120/120 & $35 / 20 / 25 / 40$ & $10 / 10 / 10 / 5$ \\
\hline 9 & $\mathrm{M} / 53$ & UHL & S-SNHL & 65/85/120/120 & $40 / 30 / 30 / 40$ & $10 / 0 / 0 / 10$ \\
\hline
\end{tabular}

Preop AC, preoperative air-conduction; Aided AC, postoperative free field air-conduction hearing; Preop BC, preoperative bone-conduction; BA, bilateral aural atresia; B, both; UA, unilateral aural atresia; COM, chronic otitis media; UHL, unilateral hearing loss; S-SNHL, sudden sensorineural hearing loss. 
Table 2. Demographic data and individual audiologic data of BAHA

\begin{tabular}{rlllccc}
\hline No. & Sex/age $(\mathrm{yr})$ & Etiology & Previous history & $\begin{array}{c}\text { Preop AC } \\
(0.5 / 1 / 2 / 4 \mathrm{kHz})\end{array}$ & $\begin{array}{c}\text { Aided AC } \\
(0.5 / 1 / 2 / 4 \mathrm{kHz})\end{array}$ & $\begin{array}{c}\text { Preop BC } \\
(0.5 / 1 / 2 / 4 \mathrm{kHz})\end{array}$ \\
\hline 1 & $\mathrm{M} / 40$ & BA & Otoplasty (B) & $70 / 60 / 60 / 60$ & $15 / 15 / 20 / 20$ & $5 / 20 / 30 / 30$ \\
2 & M/23 & BA & Meatoplasty(B) & $55 / 55 / 45 / 100$ & $25 / 20 / 30 / 70$ & $15 / 0 / 20 / 40$ \\
3 & F/12 & BA & TC & $65 / 60 / 55 / 60$ & $25 / 20 / 20 / 20$ & $10 / 10 / 20 / 15$ \\
4 & M/14 & BA & Otoplasty (B) & $55 / 60 / 80 / 60$ & $20 / 15 / 15 / 20$ & $5 / 10 / 25 / 15$ \\
5 & F/60 & COM & Adhesive drums & $80 / 80 / 85 / 90$ & $40 / 40 / 50 / 60$ & $35 / 30 / 40 / 40$ \\
6 & M/62 & COM & Adhesive drums & $95 / 105 / 110 / 105$ & $45 / 45 / 60 / 60$ & $40 / 50 / 75 / 65$ \\
7 & F/53 & COM & Otorrhea & $95 / 90 / 90 / 95$ & $30 / 45 / 40 / 35$ & $40 / 45 / 50 / 35$ \\
8 & F/54 & UHL & S-SNHL & $85 / 100 / 100 / 95$ & $35 / 25 / 30 / 30$ & $20 / 10 / 5 / 15$ \\
9 & M/22 & UHL & S-SNHL & $115 / 110 / 100 / 100$ & $30 / 30 / 30 / 25$ & $5 / 5 / 5 / 5$ \\
10 & M/59 & UHL & S-SNHL & $115 / 115 / 115 / 100$ & $15 / 30 / 20 / 10$ & $5 / 10 / 5 / 5$ \\
\hline
\end{tabular}

BAHA, bone-anchored hearing aids; Preop AC, preoperative air-conduction; Aided AC, postoperative free field air-conduction hearing; Preop BC, preoperative bone-conduction; BA, bilateral aural atresia; B, both; TC, Treacher Collins syndrome; COM, chronic otitis media; UHL, unilateral hearing loss; S-SNHL, sudden sensorineural hearing loss.
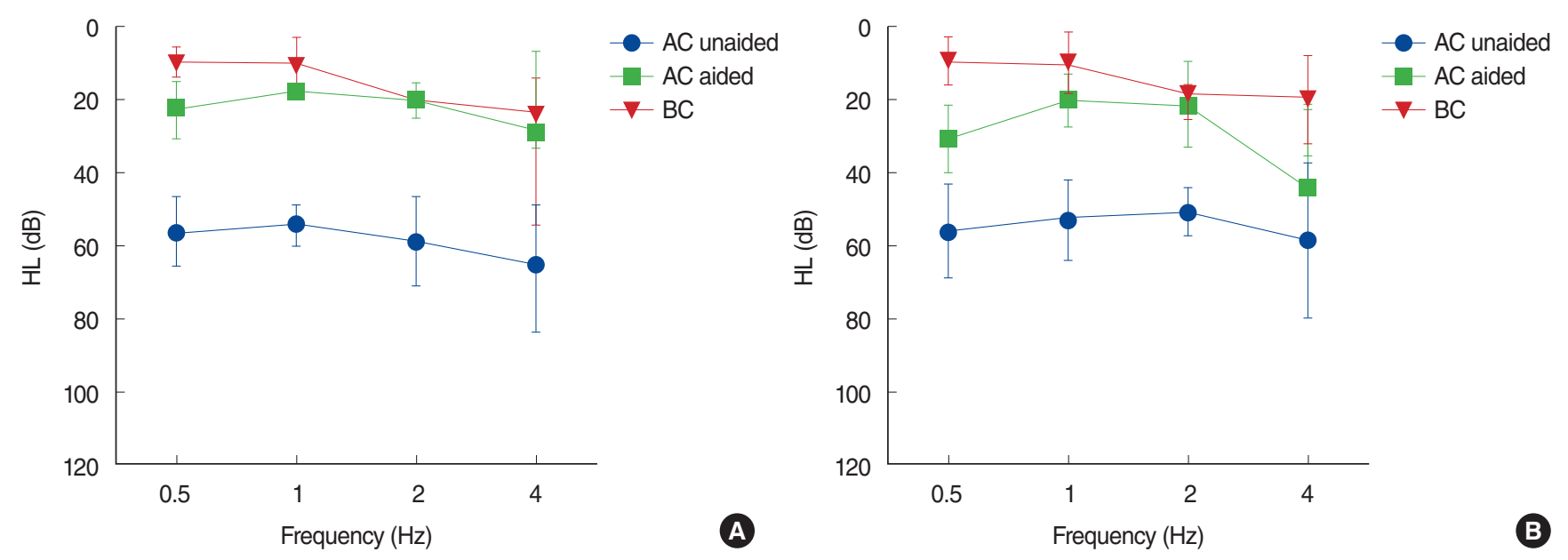

Fig. 2. The comparison of the bilateral aural atresia patients (Sophono, $n=5$; $B A H A, n=4)$. (A) Unaided mean $A C$ hearing of $B A H A$ was 62.8 $\mathrm{dB}$ and aided mean free-field $\mathrm{AC}$ hearing was $22.2 \mathrm{~dB}$. Postoperative hearing gain was $40.6 \mathrm{~dB}$. (B) Unaided mean AC hearing of Sophono was $53.7 \mathrm{~dB}$ and aided mean free-field $\mathrm{AC}$ hearing was $23.7 \mathrm{~dB}$. Postoperative hearing gain was $30 \mathrm{~dB}$. BAHA was better than the Sophono in the postoperative hearing gain, but the difference was not statistically significant. BAHA, bone-anchored hearing aids; AC, air-conduction; $\mathrm{BC}$, bone-conduction; $\mathrm{HL}$, hearing loss.

actual amplification of 2 implants. In the unilateral HL patient, the mean $\mathrm{BC}$ hearing was calculated for the better $\mathrm{BC}$ hearing ear. The postoperative $\mathrm{AB}$ gaps of BAHA were $10 \mathrm{~dB}$ at 0.5 $\mathrm{kHz}, 9.5 \mathrm{~dB}$ at $1 \mathrm{kHz}, 4 \mathrm{~dB}$ at $2 \mathrm{kHz}$, and $8.5 \mathrm{~dB}$ at $4 \mathrm{kHz}$. Postoperative $\mathrm{AB}$ gaps of Sophono were $26.6 \mathrm{~dB}$ at $0.5 \mathrm{kHz}, 16.7$ $\mathrm{dB}$ at $1 \mathrm{kHz}, 8.3 \mathrm{~dB}$ at $2 \mathrm{kHz}$, and $26.7 \mathrm{~dB}$ at $4 \mathrm{kHz}$. The difference of $\mathrm{AB}$ gap between the two groups was $16.6 \mathrm{~dB}$ at $0.5 \mathrm{kHz}$ and $18.2 \mathrm{~dB}$ at $4 \mathrm{kHz}$. The differences of postoperative $\mathrm{AB}$ gaps of $0.5 \mathrm{kHz}(P=0.0024)$ and $4 \mathrm{kHz}(P=0.02)$ between the $2 \mathrm{im}$ plants were statistically significant (Fig. 3).

The audiogram of patient who was implanted with Sophono and BAHA was shown in Fig. 4. Hearing gain of BAHA was better than Sophono in all audiologic frequencies.

\section{DISCUSSION}

In this study, the operation time of Sophono took 35 minutes longer than BAHA. During BAHA surgery with the single vertical incision without skin thinning technique, there was no need to reduce soft tissue or to elevate the flap. It just required the $2.5-\mathrm{cm}$ single post auricle incision reaching the periosteum. In the Sophono surgery, we had to do more large incision than BAHA. In addition, Sophono needed flap elevation and more drilling the skull for the internal device. The wound healing time of BAHA is longer than Sophono. However, switch on of Sophono can be started from 4 weeks after operation.

There was no major complication during surgery or postoperative period in both BAHA cases and Sophono cases. BAHA is known to develop soft tissue problems in some cases. It was re- 


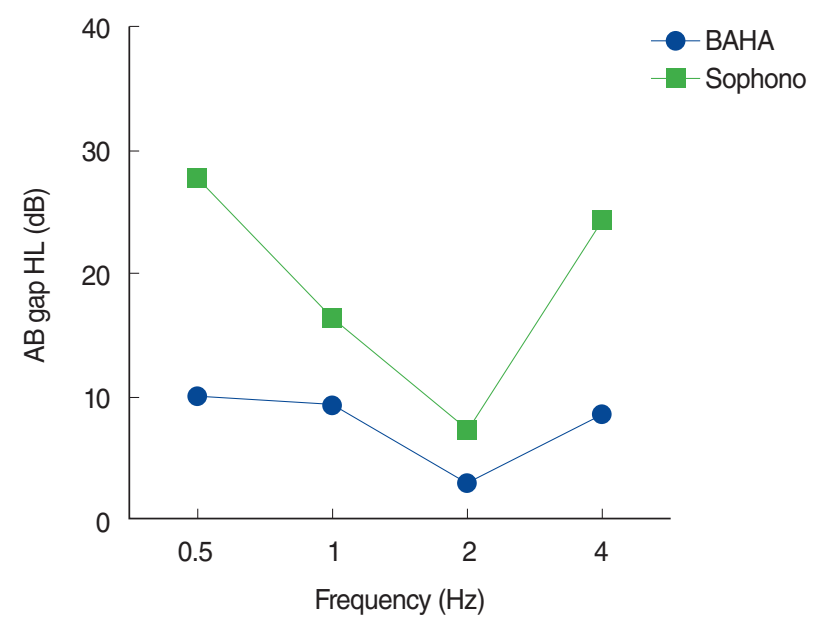

Fig. 3. The postoperative $A B$ gap comparison of all patients included in this study (Sophono, $n=9$; BAHA, $n=10$ ). We compared postoperative $\mathrm{AB}$ gap of Sophono and $\mathrm{BAHA}$ according to the frequency. BAHA was better than Sophono in the AB gap, and the difference of 0.5 and $4 \mathrm{kHz}$ was statistically significant. $A B$, air-bone; $\mathrm{BAHA}$, bone-anchored hearing aids; HL, hearing loss.

ported that there were soft tissue problems in $7.4 \%$ in BAHA patients [1]. Fixture extrusion rate due to osseointegration failure was reported to be $1.3 \%$ to $3.4 \%$ [1,2]. However, Hultcrantz [6] and Soo et al. [7] reported that a simple vertical incision without skin thinning could reduce soft tissue complications. In this study, there was no soft tissue complication during the follow-up period. BAHA in this study had only two abutment loosening cases that were solved by tightening the abutment in outpatient clinical setting.

In transcutaneous device, Siegert reported a $4 \%$ rate of temporary pressure marks as the only complication in more than 100 patients [8]. They were resolved after baseplate modification with magnet force reduction. However, O'Niel et al. [9] reported the skin complication rate was $35.7 \%$, including skin breakdown $(n=2)$ and a patient younger than 5 years required a revision surgery. Among our Sophono cases, 2 patients complained about pain around the acrylic baseplate wearing the external process. It was solved by exchanging the magnet from strength 4 to strength 2 . Meticulous care is required when patient report pain around the baseplate, especially in young children because their skin and soft tissue is thin.

In bilateral aural atresia cases of Sophono, unaided mean AC hearing was $54.5 \mathrm{~dB}$. AC hearing was improved to $29 \mathrm{~dB}$ after switch on. Postoperative hearing gain of Sophono was $25.5 \mathrm{~dB}$. Postoperative hearing gains in other reports were 29.7- to 43-dB HL [9-12]. Our result was slightly poorer than other results. It may be caused by the age of study group and previous operation history. In our Sophono study, the average age of bilateral aural atresia patients was 19.4 years (range, 5 to 33 years). Skin and soft tissue would thicken with advancing years. Thickened tissue could disturb energy transmission. Three patients previ-
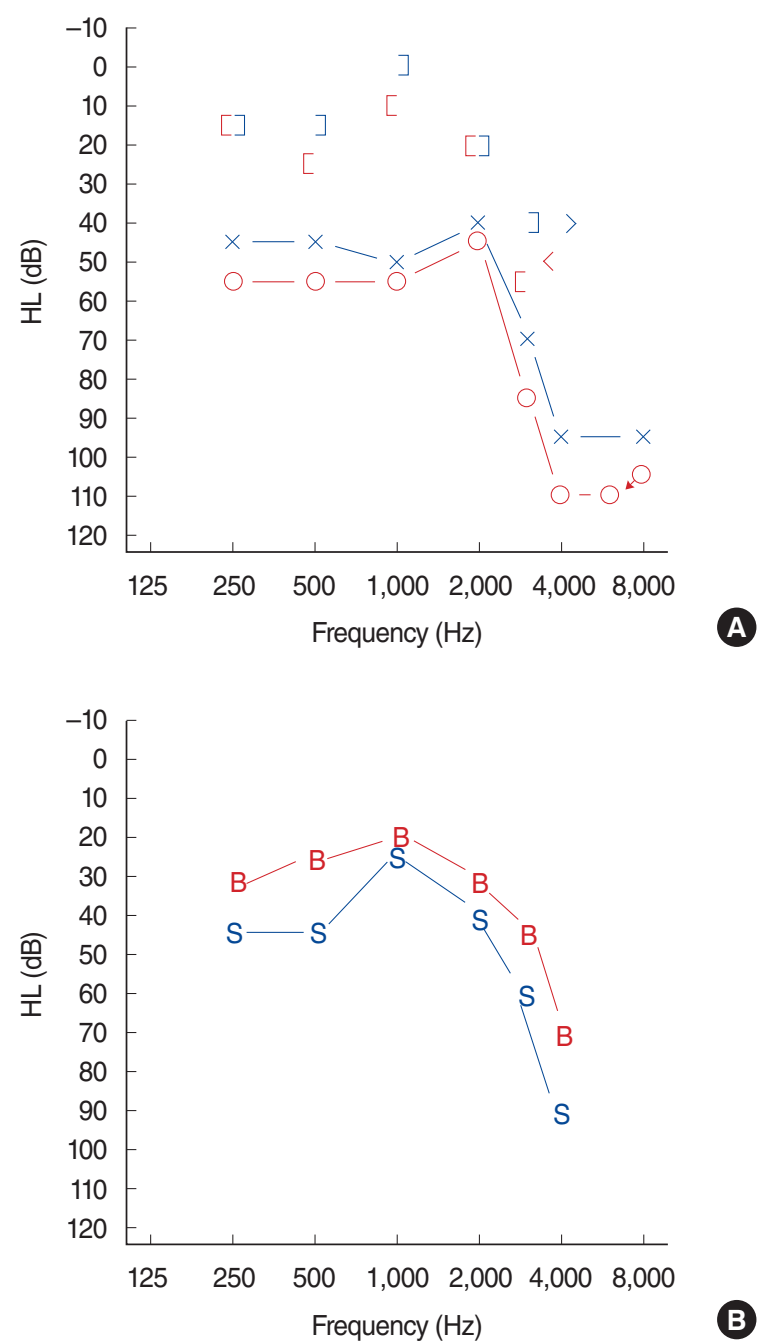

Fig. 4. The audiogram of patient who was implanted both Sophono and BAHA. Hearing gain of BAHA was better than Sophono in all audiologic frequencies. (A) Preoperative audiogram. (B) Aided audiogram. BAHA, bone-anchored hearing aids; B, BAHA; S, Sophono; $H L$, hearing loss.

ously underwent meatoplasty in this study. Operation scar also could disturb energy transmission. It was reported that postoperative hearing gain was $29.7 \mathrm{~dB}$ in 10 subtotal petrosectomy patients [10]. In that study, patients were adults with several operation histories.

When we compared the postoperative hearing gain between BAHA and Sophono in bilateral aural atresia cases, BAHA was better than Sophono. Postoperative hearing gains of BAHA and Sophono were $39.4 \mathrm{~dB}$ and $25.5 \mathrm{~dB}$, respectively. The difference was large at $0.5 \mathrm{kHz}$ and $4 \mathrm{kHz}$. The difference became clear when we compared all patients' results at each frequency for comparing the actual amplification of two implants. The difference of $A B$ gap between 2 groups was $16.6 \mathrm{~dB}$ at $0.5 \mathrm{kHz}$ and $18.2 \mathrm{~dB}$ at $4 \mathrm{kHz}$. Despite limited number and diverse causes of patients comprised in the series, the difference of postoperative 
$\mathrm{AB}$ gap at $0.5 \mathrm{kHz}$ and $4 \mathrm{kHz}$ was statistically significant. Direct bone oscillation of BAHA could be thought to improve signal transmission. In comparative study between BAHA implant and BAHA headband, a 5 to $20 \mathrm{~dB}$ increase in gain with BAHA implant compared to BAHA headband at 1 to $4 \mathrm{kHz}$ levels was reported [13]. Although Sophono fits the external processer better than headband, skin and soft tissue interference could influence signal transmission.

It was reported that BAHA users exhibited 5 to $10 \mathrm{~dB}$ better aided thresholds than Sophono users in higher frequencies (i.e., 2,000 and 4,000 Hz) [3]. However, 500 and 1,000 Hz aided hearing thresholds were similar to each other, which was slightly different from our result according to the frequency. This difference might be due to external sound processor. They used Baha Divino (Cochlear) and Sophono Alpha 1 System (Sophono Inc.) [3]. In this study, Baha BP100, Baha BP110, and Sophono Alpha 2 were used. Another problem was that Sophono patients complained of acoustic feedback when we gave more gain in low frequency. And follow-up period of each implant can influence the result.

This study is the comparative clinical study of postoperative aided hearings between BAHA and Sophono with sound processor that is the most widely used at present.

\section{CONFLICT OF INTEREST}

No potential conflict of interest relevant to this article was reported.

\section{REFERENCES}

1. House JW, Kutz JW Jr. Bone-anchored hearing aids: incidence and management of postoperative complications. Otol Neurotol. 2007 Feb;28(2):213-7.
2. Wazen JJ, Young DL, Farrugia MC, Chandrasekhar SS, Ghossaini SN, Borik J, et al. Successes and complications of the Baha system. Otol Neurotol. 2008 Dec;29(8):1115-9.

3. Hol MK, Nelissen RC, Agterberg MJ, Cremers CW, Snik AF. Comparison between a new implantable transcutaneous bone conductor and percutaneous bone-conduction hearing implant. Otol Neurotol. 2013 Aug;34(6):1071-5.

4. Zwartenkot JW, Snik AF, Mylanus EA, Mulder JJ. Amplification options for patients with mixed hearing loss. Otol Neurotol. 2014 Feb;35(2):221-6.

5. Shin JW, Park HJ, Lee SC, Park HQ, Lee HK. Single vertical incision technique without skin thinning for the bone anchored hearing aid surgery. Korean J Otorhinolaryngol-Head Neck Surg. 2012 Mar; 55(3):151-4.

6. Hultcrantz M. Outcome of the bone-anchored hearing aid procedure without skin thinning: a prospective clinical trial. Otol Neurotol. 2011 Sep;32(7):1134-9.

7. Soo GM, Tong CF, Tsang SS, Van Hasselt CA. The Hong Kong incision (direct percutaneous Baha surgery without soft tissue reduction or skin grafting): early results. In: The 2nd International Symposium on Bone Conduction Hearing - Craniofacial osseo-integration; 2009 Jun 11th-13th; Gothenburg, Sweden. 2009:33-4.

8. Siegert R. Partially implantable bone conduction hearing aids without a percutaneous abutment (Otomag): technique and preliminary clinical results. Adv Otorhinolaryngol. 2011;71:41-6.

9. O'Niel MB, Runge CL, Friedland DR, Kerschner JE. Patient outcomes in magnet-based implantable auditory assist devices. JAMA Otolaryngol Head Neck Surg. 2014 Jun;140(6):513-20.

10. Magliulo G, Turchetta R, Iannella G, Valperga di Masino R, de Vincentiis M. Sophono Alpha System and subtotal petrosectomy with external auditory canal blind sac closure. Eur Arch Otorhinolaryngol. 2015 Sep;272(9):2183-90.

11. Denoyelle F, Leboulanger N, Coudert C, Mazzaschi O, Loundon N, Vicaut E, et al. New closed skin bone-anchored implant: preliminary results in 6 children with ear atresia. Otol Neurotol. 2013 Feb;34(2): 275-81.

12. Siegert R, Kanderske J. A new semi-implantable transcutaneous bone conduction device: clinical, surgical, and audiologic outcomes in patients with congenital ear canal atresia. Otol Neurotol. 2013 Jul;34(5):927-34.

13. Verstraeten N, Zarowski AJ, Somers T, Riff D, Offeciers EF. Comparison of the audiologic results obtained with the bone-anchored hearing aid attached to the headband, the testband, and to the "snap" abutment. Otol Neurotol. 2009 Jan;30(1):70-5. 